\title{
QUEEN'S
UNIVERSITY
BELFAST
}

\section{Modelling of mechanical failure due to constrained thermal expansion at the lightning arc attachment point in carbon fibre epoxy composite}

material

Foster, P., Abdelal, G., \& Murphy, A. (2018). Modelling of mechanical failure due to constrained thermal expansion at the lightning arc attachment point in carbon fibre epoxy composite material. Engineering Failure Analysis. https://doi.org/10.1016/j.engfailanal.2018.08.003

\section{Published in:}

Engineering Failure Analysis

\section{Document Version:}

Peer reviewed version

Queen's University Belfast - Research Portal:

Link to publication record in Queen's University Belfast Research Portal

\section{Publisher rights}

Copyright 2018 Elsevier.

This manuscript is distributed under a Creative Commons Attribution-NonCommercial-NoDerivs License

(https://creativecommons.org/licenses/by-nc-nd/4.0/), which permits distribution and reproduction for non-commercial purposes, provided the author and source are cited.

\section{General rights}

Copyright for the publications made accessible via the Queen's University Belfast Research Portal is retained by the author(s) and / or other copyright owners and it is a condition of accessing these publications that users recognise and abide by the legal requirements associated with these rights.

\section{Take down policy}

The Research Portal is Queen's institutional repository that provides access to Queen's research output. Every effort has been made to ensure that content in the Research Portal does not infringe any person's rights, or applicable UK laws. If you discover content in the

Research Portal that you believe breaches copyright or violates any law, please contact openaccess@qub.ac.uk. 


\title{
Modelling of mechanical failure due to constrained thermal expansion at
}

\section{the lightning arc attachment point in carbon fibre epoxy composite}

\author{
material \\ P Foster $^{\mathrm{a}}$, G Abdelal $^{\mathrm{a}}$, A Murphy $^{\mathrm{a},+}$ \\ ${ }^{a}$ School of Mechanical and Aerospace Engineering, Queen's University Belfast, Ashby \\ Building, Belfast. Northern Ireland, U.K. BT9 5 AH \\ ${ }^{+}$Corresponding author:Tel.: +44289097 4095; E-mail: a.murphy@qub.ac.uk
}

\begin{abstract}
Examination of artificial lightning strike test damage suggests that mechanical loading contributes to some aspects of composite material degradation and failure. So far numerical work has focused on modelling resistive heating from the electrical load and a very limited number of studies have considered the thermal induced mechanical effects. Also preceding work which has modelled the effect of acoustic pressure loading has predicted the influence on specimen damage to be negligible. Thus the objective of this paper is to quantify the potential magnitude of the internal specimen mechanical loading resulting from electrical load induced thermal expansion. This is achieved through a simulation study and the definition of a bespoke modelling procedure to map specimen time dependent temperature from a thermal-electric analysis into a mechanical thermal-expansion analysis. The study compares predicted behaviour with measured test specimen damage. The results for the first time quantify the potential scale of loading resulting from constrained thermal expansion, the dimensions of induced damage and the strain rate magnitudes required for accurate material representation.
\end{abstract}

Keywords: Lightning Strike; constrained thermal expansion; composite material; strain rate effects; Finite Element Modelling. 


\subsection{Introduction}

From measurements taken on test aircraft flown purposely into active lightning storms [1-3] standardised lightning intensity and current waveforms have been established for laboratory certification testing [4-5]. Examination of composite specimens under these standardised test conditions suggests that mechanical loading contributes to some aspects of lightning strike damage [6-8]. Experimental results on composite specimens typically exhibit three damage modes; material ablation and decomposition, fractured fibres and cracked matrix material, and delamination of the laminate [8-18].

However, there is still limited understanding of the mechanisms during a lightning strike which lead to damage, partly due to the complex thermal, electrical, electromagnetic and mechanical components of the event [19-21], and partly due to the limited number of artificial lightning strike tests which have been published. The major challenge with testing is the speed and intensity of a lightning strike which makes it very difficult to directly acquire high resolution physical measurements during a test [13]. Post-test inspection of the damage is also complicated given the different damage modes, their interconnections and the damage concentration at the lightning arc attachment point.

Numerical simulations have the potential to generate further understanding of the behaviour during experiments and reduce the volume of testing typically required for new design certification. To date numerical studies have mostly focused on modelling resistive heating from the electrical load [22-24] but other loading mechanics have also been studied (electromagnetic and acoustic pressure, internal explosive loads [6-7, 18]) but with significantly less attention. Thus the objective of this paper is to investigate the potential contribution of the internal specimen mechanical forces due to thermal expansion. This will be achieved through a simulation study using an established modelling approach for thermal- 
electric resistive heating, and adding a mechanical simulation phase which represents specimen internal thermal expansion. A bespoke modelling procedure to appropriately map the specimen time dependent temperature from the thermal-electric simulation into an appropriate mechanical thermal-expansion model will be defined and demonstrated.

First focusing on experimental studies [8-18] these have identified the previously noted damage modes occurring in composite specimens. However a significant range in the form and scale of each type of damage is found generally in the literature. This inconsistency is due to the variation in the individual specimen designs (materials, material stacking sequence, lightning protection system), differing intensity and current waveforms, and test setup (varying distance between the specimen and the discharge probe, varying specimen fixturing and boundary conditions). In general the damage can be divided into three zones $[7,25]$ :

- Severe damage zone - identified as an area dark in appearance with char residue at the centre of the damage and with the greatest depth of damage. This zone is characterised by an absence and/or broken fibres, with the majority of surface resin absent. Signs of thermal and mechanical loads are present, evidenced by areas with ash and charring (thermal) and sharp resin morphology and fractured fibres (mechanical).

- Moderate damage zone - identified as a surface damage area surrounding the severe damage zone. This zone is characterised by damaged and absence surface resin and may include limited zones with fractured fibres (in the form of tufts of fibres protruding from the resin). Electron microscopy scanning of the surface indicates that fibres are well covered with resin and the resin fracture surface has relatively sharp and rugged morphology, consistent with mechanical damage. 
- Sub-surface damage zone - identified as damage within the laminate. This may include intralaminar and interlaminar matrix cracking, and thus again suggests some form of mechanical loading.

Moreover experimental authors note probable or possible causes of the damage. In particular resistive heating is consistently identified to cause a significant amount of the measured damage but does not completely explain all the damage morphology which suggests some mechanical forces are present and significant. The missing resin around the fibre has been attributed by the vast majority of lightning authors to resistive heating of the composite $[10-11,14-15,18,21]$. Some authors $[11,14]$ have also suggested that the thermal load from the arc channel may have a significant contribution while others have dismissed this load as minimal compared to the resistive heating [8]. Various authors propose that a blast force is the mechanical force responsible for fibre breakage but there remains disagreement as to the cause of the blast force. Three non-thermal loads are generally referenced in the experimental literature - pressure loads induced by acoustic and electromagnetic effects, or explosive loads resulting from rapid heating and the expansion or explosion of internal trapped gases (gas build-up due to resin decomposition). However there are only a limited number of studies which focus on these mechanical loading effects.

A number of authors $[7-8,14,18,26-29]$ specifically discuss or investigate mechanical loading effects. Chemartin et al. [8], Gineste et al. [26] and Kawakami [14] describe the arc plasma physics which results in pressure loading and outline the use of simplifications and theoretical equations or numerical simulations, based on magnetohydrodynamics, for the prediction of magnetic and acoustic pressures. Haigh [9], Gineste et al. [26] and Lepetit et al. [27] attempt to experimentally infer the pressure loads during 
testing based on a variety of test setups and specimen materials. Lepetit et al. [27] based on modelling and modified experiments concludes that of their three examined loads (Joule effect on the surface, acoustic pressure, magnetic pressure) that the acoustic and magnetic contributions are dominant, and have roughly comparable weights.

Munoz et al. [18] applied a pressure load to a composite specimen based on Chemartin's [8] proposed equation for the lightning impact shock wave. The idealised pressure wave was based on the electro-magnetic pinching, electromagnetic flux and the resulting expansion wave of the lightning channel. Both mechanical and thermal simulations were undertaken but results were considered separately. The mechanical analysis did not predict failure according to the Tsai-Wu failure criteria, however Munoz et al. [18] concluded that 'although the elements did not fail, some matrix cracking might occur through the thickness of the laminate'. Foster et al. [7] models the range of pressure loads described in the literature, including $[8,9,14,26]$, and compares the explicit Finite Element (FE) simulation predictions with measured test specimen damage. The results demonstrate that the proposed pressure loads have a negligible contribution to the overall scale of experimental damage.

Specifically for painted specimens, Lepetit et al. [28] proposes a further mechanical loading mechanism is active, confined surface explosion, which increases damage. In a similar vein Liu et al. [29], models a high explosive burn to represent a blow-out effect due to trapped gas from resin decomposition. Liu et al. [29] only offers qualitative comparison but suggests the simulation predictions compare well with damage patterns from test specimens.

Overall the preceding literature examines a small range of mechanical loading mechanisms and generally assesses, for non-painted specimens, that these are less significant in damage creation than resistive heating. The preceding literature does not consider the potential contribution of the internal specimen mechanical stresses due to the thermal 
expansion resulting from this resistive heating. Given the lack of literature on this mechanical loading mechanism it is appropriate to study if thermal expansion, via joule heating, is an important contributor to the measured experimental damage - in particular associated with the moderate damage zone as described above. To this end the subsequent section describes the modelling undertaken to address this hypothesis.

\subsection{Modelling procedure}

\subsection{Thermal strains and stresses}

Strains that occur as a result of material temperature change are identified as thermal strains and are related to the temperature variation by thermal expansion coefficients. If induced thermal strains are constrained, because deformations are constrained, then thermal stresses will result. In an orthotropic material the thermal expansion coefficient will vary in all three directions resulting in varying thermal strain for each direction for a change in temperature. In a composite laminate the combination of significantly varying orthotropic stiffness properties and thermal expansion properties can result in individual plies constraining neighbouring ply deformations and creating significant internal stresses and vice versa. In fact Parlevliet et al. [30] identifies thermal effects at three levels: the macro-mechanical level as described above - a ply to ply mismatch; the micro-mechanical level, where there is a mismatch of thermal expansion coefficient between the fibres and the matrix; the laminate level, considering temperature gradients through the laminate thickness.

From the preceding lightning strike thermal electric simulations [18, 20-25] composite specimen materials reach high temperatures, $>1,000^{\circ} \mathrm{C}$, over short time periods, $<$ 
$50 \mu$ s. Similar temperature conditions are experienced during laser pulse tests with beam densities of the order of $\mathrm{GW} / \mathrm{m}^{2}$ applied over milliseconds [31-35]. In these works maximum surface temperatures reached are between 2,000 and $3,000^{\circ} \mathrm{C}$. The thermal loading of these specimens thus compares well with the thermal behaviour observed during lightning strike testing. A significant advantage of reviewing this work is that it allows separation of the thermal from electrical loads when trying to assess thermal effects. The reported laser pulse damage consists of: matrix cracking, ejection of fibres from resin and fibre fracture. At lower intensity beam pulses, erosion of the matrix occurs through small particle ejection from the specimen surface (via sublimation). At higher beam intensity pulses, larger particles (carbon fibres or carbon fibre fragments) are ejected from the specimen and matrix cracking is observed [31-33]. The resulting cavities, for example [31-32], compare favourably with the pictures and description of the moderate damage areas under lightning strike. The laser pulse test authors generally agree on the damage mechanisms: during the heating phase the matrix expands more than the fibre. The fibres then prevent expansion causing large compressive stresses particularly at the interface between fibre and resin. This stress is then released by the formation of micro cracks which is associated with the ejection of fibres from the resin. Significantly then, both temperature and the rate of temperature change are important characteristics to be observed within the simulation results.

\subsection{Baseline experiment}

In order to quantify the potential of constrained thermal expansion behaviour to cause specimen damage a preceding experimental setup is modelled [11]. In this test the specimen was placed on a grounded copper sheet on a glass fibre composite test jig. A discharge probe tip was located approximately 2.0 to $3.0 \mathrm{~mm}$ from the specimen surface. The test specimen (a 
$4.704 \mathrm{~mm}$ thick laminate plate (IM600/133), stacking sequence $(45 / 0 /-45 / 90)_{4 \mathrm{~S}}$, was subjected to a peak current of $40 \mathrm{kA}$, with an electrical charge of $0.85 \mathrm{C}$ and an action integral of $22,000 \mathrm{~A}^{2} \mathrm{~s}$. The impulse waveform represented a first return stroke with a $4 \mu \mathrm{s}$ rise time from $10 \%$ to $90 \%$ of the maximum current, and a time of $20 \mu$ s to a post-peak $50 \%$ maximum current. In order to aid the comparison between the experimental results and simulation predictions the damage geometry was analysed and the dimensions of the individual damage zones numerically quantified by this author, Figure 1.

\subsection{Thermal electric model}

Using the FE method and employing explicit thermal-electric analysis, it is possible to model the temperature generation and temperature transfer due to resistive heating from electrical arc loading [18, 20-25]. Herein the thermal-electric analysis is carried out in ABAQUS Explicit and uses C3D8R elements. The temperature results taken from the thermal-electric model will then be used in the thermal expansion analysis.

The electric current load with respect to time is applied to an area at the centre of the specimen using a series of surface current loads. The shape of each surface current load is defined using a field equation which enables the application of circular or elliptical load patterns. Using multiple surface current loads and by varying their amplitude with time it is possible to create both moving and expanding arc radius patterns [25]. This approach thus enables the representation of a moving filament of arc at the centre of an expanding arc. As limited experimental data is available which defines accurately the arc attachment behaviour the modelled behaviour is based on the general experimental description of behaviour during testing [11] and plasma simulation work of similar test setups $[8,20]$. Further it is initially 
assumed that half the total electric load is associated with the moving arc component and half associated with the expanding arc component [25].

Figure 2 illustrates the method applied to introduce the expanding current load. The elliptical expanding component of the arc is assumed to apply a uniform current load with the rate of expansion corresponding to Chemartin's arc radius versus time model [8]. Each new load, with a larger radius, is introduced and the previous load with a smaller radius is cancelled. The loads are introduced and cancelled using an amplitude function, by raising the amplitude from zero and then reducing the amplitude back to zero. Equation 1 presents the field equation used to define the elliptical expanding arc. $x=y=z=0$ describes the centre point on the top surface of the specimen. In Equation 1, $\lfloor z\rfloor$ is the largest integer less than or equal to $\mathrm{z},\lceil\mathrm{z}\rceil$ is the smallest integer greater than or equal to $\mathrm{z}$. $\mathrm{a}$ and $\mathrm{b}$ are the principal radii of the arc over which the load is applied.

The movement is assumed to be transverse across the specimen - aligned with the $0^{\circ}$ fibre direction. A movement of four arc diameters is initially modelled with a load sequence starting in the centre position and then looping to one side, back to centre, then to the other side, and back to centre, repeat. The arc position dwells on each location for $2.5 \times 10^{-6}$ seconds for the duration of the electric loading [25].

$$
\text { Field }=\left\lceil\left\lfloor\frac{1}{\sqrt{\frac{x^{2}}{a^{2}}+\frac{y^{2}}{b^{2}}}}\right\rfloor /\left(\left\lfloor\frac{1}{\sqrt{\frac{x^{2}}{a^{2}}+\frac{y^{2}}{b^{2}}}}\right\rfloor+1\right)\right.
$$


The key behaviour during the analysis is located at the centre of the specimen and therefore a simulation mesh was developed which was refined at the centre and coarsened toward the specimen edges. A mesh convergence study was undertaken which examined the predicted temperature contour at the specimen surface and the predicted temperature contour through the specimen depth. Convergence was considered to have occurred with an in-plane mesh seed of $1.5 \mathrm{~mm}$ and 2 elements through the thickness of each of the top 8 plies. Figure 3 illustrates the final specimen mesh used in all analysis along with an overview of the analysis boundary conditions.

\subsection{Mechanical model}

The thermal expansion analysis is carried out as a coupled temperature displacement analysis. This is a high speed event due to the heating rate and resulting thermal expansion rate involved and is thus carried out in ABAQUS Explicit and uses C3D8R elements. The temperature results taken from the thermal-electric model are used in the thermal expansion analysis therefore, for consistency with the thermal-electric model, the same mesh is also used. There are a number of possible methods by which results from the thermal-electric analysis can be incorporated within the thermal expansion analysis. Herein a python script is used to extract the temperature results over time for each node from the thermal-electric analysis and to input this data into the thermal expansion analysis. Figure 4 presents an overview of the process used to transfer the temperature data.

\subsection{Material behaviour}


Mechanical and thermal properties are required for the analysis however the event to be modelled comprises high temperature, high heating rate and high strain-rate. Together these effects will influence the properties exhibited by the material. Mechanical and thermal properties are available for similar material systems but not at the extremely high temperature-rates and strain-rates surrounding the arc attachment point. Data and methods are proposed to account for the high heating rates but methods for characterising composite materials considering the required strain-rates are limited. Strain rates up to $1000 \mathrm{~s}^{-1}$ may be obtained using a split Hopkinson pressure bar [36], but beyond this level available data is limited for the studied material. Thus no single material data set is available which represents the high heating rates, high temperatures and high strain-rates expected during a lightning strike test. Thus given the uncertainties associated with the material behaviour the simulation study systematically introduces the individual dependencies to allow a first understanding of the importance of each:

- Temperature dependent material properties - An initial analysis is carried out using only temperature dependent expansion and mechanical properties, with temperature rate and strain rate effects not represented. Non-linear expansion properties are obtained for the ply fibre, transverse and through-thickness directions from [37]. Above the resin glass transition temperature expansion properties in the fibre direction are assumed to be constant (equivalent to those at the glass transition temperature). Transverse and throughthickness direction expansion coefficients are assumed to increase linearly until resin decomposition begins (initially modelled to start at $300^{\circ} \mathrm{C}$ ) [25]. The expansion coefficients are then modelled to linearly decrease to zero at complete decomposition (idealised to occur at $500^{\circ} \mathrm{C}$ ) [25]. Fibre ablation is modelled between $3,316^{\circ} \mathrm{C}$ and $3,334^{\circ} \mathrm{C}$ [21]. Fibre direction mechanical properties are assumed to remain unchanged with temperature but ply transverse and through-thickness elastic modulus are assumed to 
reduce by a factor of four at the glass transition temperature [38], including the shear modulus. Matrix failure stress and strain are idealised to increase and decrease by the same proportions (factor of four) respectively above the glass transition temperature. Finally as noted before the temperature boundary conditions from the thermal-electric analysis are enforced at every node in the analysis therefore thermal properties are not modelled to be influenced by temperature.

- $\quad$ Temperature and temperature rate dependent material properties - Preceding work, using Thermal Gravimetric Analysis (TGA) to determine material decomposition behaviour, has demonstrated a lag in material behaviour with increasing heating rates [22]. To represent this effect in simulation a temperature offset on material effects has widely been proposed. Ogasawara et al. [22], based on the extrapolation of measured TGA results proposes for heating rates of the order of $10,000^{\circ}$ minute (assumed for lightning strikes) a thermal lag offset of $200^{\circ} \mathrm{C}$ can be used to represent the temperature rate effect. Thus herein to add the temperature rate effect to the temperature dependent material properties (above) an offset of $200^{\circ} \mathrm{C}$ is applied to the referenced temperatures (i.e. glass transition, decomposition and ablation temperatures). Comparison of the predicted results (offset vs. non-offset) will enable a first assessment of the impact of temperature rate.

- $\quad$ Temperature, temperature rate and strain rate dependent material properties - High strain rates have been demonstrated to increase the elastic modulus and failure stress of materials [36, 39-41]. Thus assuming a number of strain-rates and using Goldberg's equation [36] the elastic properties may be adjusted to represent specific strain rates. Two different strain rates are examined to establish the sensitivity of the analysis. Based on preliminary analysis two strain rates $\left(1 \times 10^{3} \mathrm{~s}^{-1}\right.$ and $\left.1 \times 10^{4} \mathrm{~s}^{-1}\right)$ were identified based on the average conditions over the measured damage zones (the moderate and severe damage 
zones respectively). All other temperature dependent expansion and mechanical properties remain unchanged from the preceding study.

Through this stepwise representation of material behaviour a better understanding will be gained on the influence of material effects on the prediction of thermal expansion.

\subsection{Damage behaviour}

Much research has focused on using the Finite Element method for the prediction of composite material damage resulting from laminate transverse impact and blast loading [4248]. Various failure criteria can be applied to predict the onset of fibre or matrix failure. Moreover post-initiation energy based or displacement based damage evolution models utilising principles of material degradation have been demonstrated to predict damage progression. Using contact modelling methods to simulate cohesive behaviour at ply interfaces, the initiation and growth of delamination has also been successfully modelled.

Herein the modelling approach used by Phadnis [43] and validated for transverse impact loads is used as an efficient, mature and robust approach. The Hashin failure criteria is used to predict intralaminar ply failure in the fibre direction accounting for fibre damage in compression and tension. This is also used for tensile failure in the directions transverse to the fibre direction were the matrix failure mode is dominant. However studies have shown that this approach struggles to accurately predict matrix compressive failure as greater direct transverse compressive stress will require greater shear stresses to cause matrix failure. An alternative matrix compressive failure model proposed by Puck [49] is used instead. While this is proposed for the in-plane transverse direction, this failure model is also extended to the through thickness direction as this is also a matrix dominated direction. Delamination is modelled using the in-built cohesive surface option in ABAQUS/Explicit with an initial 
elastic region, initial failure and damage progression until ultimate failure. The bi-linear traction-separation relationship is used with failure initiation governed by the quadratic stress criterion. Delamination is propagated using the mixed-mode relationship proposed by Benzegagh and Kenane [50].

\subsection{Results and Discussion}

Simulations of the experimental setup outlined in Section 2.2 (Baseline experiment) are now presented based on the modelling methodology outlined in Section 2.3 to 2.6; first the predicted electric induced thermal behaviour is described (Section 3.1), before the resulting mechanical behaviour is described (Section 3.2) and the impact of material idealisation discussed (Section 3.3).

\subsection{Predicted specimen thermal behaviour}

A brief description of the temperature development during the thermal-electric and the subsequent heat transfer analysis are first presented, Figure 5 and Figure 6 respectively. In the thermal-electric analysis the temperatures rise in the top ply at the centre of the specimen and propagate through the top ply and down through the specimen thickness. The maximum temperatures in the simulation are reached at the end of this step. The temperatures in the specimen then reduce throughout the heat transfer analysis as heat diffuses throughout the specimen. During this second phase of analysis heat transfers to plies further beneath the already heated plies during the thermal-electric step. The temperatures reached in these plies are significantly lower than temperatures reached during the initial thermal-electric step. 


\subsection{Predicted specimen mechanical behaviour}

\section{Temperature dependent material properties}

The maximum stresses and strains during the analysis are presented in Table 1 for the ply fibre, transverse and through-thickness directions. Figures 7-8 plots, along the centre line of the specimen, the progression over time of the largest stresses and strains. These occur in the ply transverse direction for stress $\left(\sigma_{22}\right)$ Figure 7 , and in the ply through-thickness direction for strain $\left(\varepsilon_{\mathrm{zz}}\right)$, Figure 8 . The magnitude of stresses and strains in the other directions are significantly smaller and negligible in comparison with their failure criteria, Table 1. Therefore maximum stress and strain failure criteria may be used to assess $\sigma_{22}$ and $\varepsilon_{\mathrm{zz}}$. The transverse fibre direction stresses build during the thermal loading to be compressive in the upper plies of the specimen with resulting balancing tensile stresses in the plies below. The thermal loading directly results in tensile through-thickness strains in the upper plies which exert a through-thickness load and creates compressive strains in the plies below.

Only the through-thickness tensile strains reach a level to cause failure. Figure 9 presents the predicted area of failure for the top five plies. The failure area is largest on the top ply becoming smaller further through the plate thickness until the fifth ply. The damage zone is similar in shape but larger in area than the severe damage zone and smaller in area than the moderate damage zone, Figure 1. However it is important to remember that the damage predicted here represents only mechanical damage and not the direct thermal degradation effects

$\underline{\text { Temperature and temperature rate dependent material properties }}$ 
Table 1 summarises the maximum stresses and strains in comparison with the first simulation results. With the introduction of the thermal lag, the peak transverse stress and throughthickness strain have increased, notably now the transverse stress is doubled and predicts failure along with the through-thickness tensile strain. Transverse stress failure as the stress reaches above $72.5 \mathrm{MPa}$ (failure stress above $\mathrm{T}_{g}$ ) before the onset of the delayed $\mathrm{T}_{g}$. When $\mathrm{T}_{\mathrm{g}}$ is reached, the failure stress reduces however the current stress does not reduce and is above the new failure stress. Further experimental material data is required to determine if this material behaviour is physically accurate or if viscous material flow occurs when the temperature rises which would relax the material thereby reducing the stress. Therefore temperature history material data is necessary for future simulation studies. Figure 10 presents the predicted area of through-thickness strain failure for the top five plies and transverse stress failure. The through-thickness strain failure area has reduced and is now smaller than the severe damage area, while the damage depth remains similar to the experimental severe damage depth, reaching the fifth ply. Transverse stress failure occurs further from the centre of the plate outside the through-thickness strain failure area and increases the failure area by $550 \mathrm{~mm}^{2}$. Thus the introduction of the thermal lag has resulted in larger peak through-thickness strains and transverse stresses but strain failure is confined to smaller regions within each of the top five plies. Predicted transverse stress failure increases the failure area therefore temperature history material data is required for this analysis.

The largest strain rates occur in this analysis during the first $2.5 \times 10^{-6}$ seconds when the rate of temperature change is the greatest, and occur at the top surface towards the centre of the specimen. Figure 11 shows the area where the strain-rate reaches over $10^{4} \mathrm{~s}^{-1}$ (a strain rate magnitude typically associated with explosive events). This area is $1080 \mathrm{~mm}^{2}$, marginally greater than the severe damage area. The explosive strain rate (i.e. $>10^{4} \mathrm{~s}^{-1}$ ) reaches a width of $28 \mathrm{~mm}$ and a depth of $2.5 \mathrm{~mm}$ (third ply). This compares well with the 
section microscopy view of the experimental damage, where the width of ply lift reaches the third ply and is approximately equal to $28 \mathrm{~mm}$, Figure 11.

$\underline{\text { Temperature, temperature rate and strain rate dependent material properties }}$

Table 2 presents the predicted peak transverse stresses and through-thickness strains with the modified elastic moduli for the selected strain rates $\left(1 \times 10^{3} \mathrm{~s}^{-1}\right.$ and $\left.1 \times 10^{4} \mathrm{~s}^{-1}\right)$. These strain rates are represented by factoring the elastic modulus in each simulation by 1.5 and 1.8 respectively (based on Goldberg's equation [36]). From Table 2, the transverse stresses increase by a similar factor as the increase in modelled modulus, while the through-thickness strains remain similar. Assuming the failure stress and failure strain increase and decrease by the same factor as the modulus, the transverse stress failure will not vary significantly with the modelled strain rate effect (i.e. transverse stress and failure stress increase by the same factor). However the through-thickness strain remains the same but the failure strain is reduced by the factor applied to the modulus. Therefore the areas of through-thickness strain failure increase with the increasing strain rate effects, Figure 12. These results, although preliminary, demonstrate the potential sensitivity of predictions to strain rate effects and the need for material data under these very specific and extreme conditions.

\subsection{Influence of material idealisation}


Generally the predicted damage, in terms of surface area and depth, is comparable with measured specimen damage, Figure 1, which includes damage resulting from both mechanical and thermal loading. Comparing damage predicted with preceding simulations representing resistive heating and thermal damage - the damage resulting from constrained thermal expansion is generally greater in surface area (e.g. $\approx 200 \%$ [25]) and equivalent in damage depth.

Examining the simulation predictions with and without temperature and strain rate material behaviour (Figure 9-11) it can be seen that the predicted damage is visibly sensitive to these rate effects. In particular the results show that the introduction of a thermal lag due to a large heating rate can significantly reduce the predicted failure area; herein a $200^{\circ} \mathrm{C}$ temperature lag resulted in a $\approx 50 \%$ reduction in the predicted area of damage. Moreover, modelling the influence of strain rate can increase the predicted damage area; with $a \approx 30 \%$ increase observed in damage area with an adjustment to mechanical properties representing an idealised strain rate shift (from $1 \times 10^{3}$ to $1 \times 10^{4} \mathrm{~s}^{-1}$ ). Both sets of results illustrate the significance of material properties and the need for new test methods to generate material properties for the combination of extreme conditions witnessed during a lightning strike.

\subsection{Conclusions}

The paper demonstrates the modelling of constrained thermal expansion considering the impact of temperature, temperature rate and strain rate dependent material properties. The study modelled a lightning strike test setup and compared the predicted behaviour with

measured test specimen damage. The results indicate that mechanical failure due to 
constrained thermal expansion can result in damage comparable to the scale and shape of measured test specimen damage. The simulation results predict damage which is greater in scale than that typically predicted when representing resistive heating and thermal material degradation. The damage for the studied experimental setup, with the inclusion of constrained thermal expansion is predicted with a $\approx 200 \%$ greater surface area but with an equivalent damage depth when compared to preceding simulations representing only resistive heating. Moreover the simulations also reveal the significant sensitivity of damage prediction to the modelling of temperature rate and strain rate effects. Variation in surface damage area predictions of $30 \%$ and $50 \%$ have been demonstrated respectively with the introduction of temperature rate dependent material properties and a change in idealisation for strain rate dependent material properties. Ultimately the work defines the need for improved knowledge and data for the modelling of materials under lightning strike test conditions - to represent completely the influence of temperature, temperature history, temperature rate and strain rate effects.

\section{Acknowledgment}

Financial support from the Department for Employment and Learning (Northern Ireland) for the Ph.D. research of P. Foster is gratefully acknowledged. 


\section{Reference}

[1] 1980 direct lightning strike data. NASA Technical Memorandum 81946, NASA Langley Research Centre, Hampton, VA, 1982.

[2] P. Lalande, A. Bondiou-Clergie, and P. Laroche. Studying Aircraft Lightning Strokes. Aerospace Engineering, 94:39-42, 1999.

[3] J. Moreau, J. Alliot, and V. Mazur. Aircraft Lightning Initiation and Interception from In Situ Electric Measurements and Fast Video Observations. Journal of Geophysical Research, Vol. 97, pp. 903-912, 1992.

[4] Aerospace recommended practice arp 5412. Aircraft Lightning Environment and Related Test Waveforms, SAE.1999.

[5] Aerospace recommended practice arp 5414. Aircraft Lightning Zoning, SAE. 1999.

[6] Z. Liu, Z. Yue, F. Wang, and Y. Ji. Combining analysis of coupled electrical-thermal and blow-off impulse effects on composite laminate induced by lightning strike. Applied Composite Materials. Vol. 22, Issue 2, pp 189-207, April 2015

[7] P. Foster, G. Abdelal, A. Murphy. Quantifying the Influence of Lightning Strike Pressure Loading on Composite Specimen Damage. Accepted for publication in Applied Composite Materials, 2018

[8] L. Chemartin, P. Lalande, B. Peyrou, A. Cahzottes, and P. Elias. Direct Affects of Lightning on Aircraft Structure: Analysis of the Thermal, Electrical and Mechanical Constraints. Journal of Aerospace Lab, Vol. 5, 2012

[9] S. Haigh. Impulse Effects During Simulated Lightning Attachments to Lightweight Composite Panels. Presented at Int. Aerospace Ground Conf. on Lightning and Static Electricity, Paris, France. 2007.

[10] P. Feraboli and M. Miller. Damage resistance and tolerance of carbon/epoxy composite coupons subjected to simulated lightning strike. (98195-2400), Presented at 
AIAA/ASME/ASCE/AHS/ASC Structures, Structural Dynamics and Materials Conference, Palm Springs, California, May 2009

[11] Y. Hirano, S. Katsumata, Y. Iwahori, and A. Todoroki. Artificial Lightning Testing on Graphite/Epoxy Composite Laminate. Composites Part A: Applied Science and Manufacturing, Volume 41, Issue 10, Pages 1461-1470, 2010

[12] P. Feraboli and H. Kawakami. Damage of Carbon/Epoxy Composite Plates Subjected to Mechanical Impact and Simulated Lightning. Journal of Aircraft, Vol. 47(00218669/10), pp. 999-1012, 2010.

[13] T. Sonehara ,Y. Hirano, H. Kusano, N. Tokuoka. Visualization of Lightning Impulse Current Discharge on CFRP Laminate. International Conference on Lightning Protection (ICLP), Shanghai, China, 2014

[14] H. Kawakami. Lightning strike induced damage mechanisms of carbon fiber composites. PhD Thesis, University of Washington, 2011.

[15] H. Kawakami and P. Feraboli. Lightning Strike Damage Resistance and Tolerance of Scarf-Repaired Mesh-Protected Carbon Fiber Composites. Composites: Part A, Vol. 42, pp. $1247-1262,2011$.

[16] N. Hosokawa, T. Ooto, S. Kubo, M. Anzai, A. Yoshiya, and A. Nakagoshi. Lightning strike protection for composite laminates by pitch-based carbon fibre skin. Presented at The 19th International Conference on Composite Materials, Montreal, Canada. July 2013.

[17] S. Yamashita, I. Ohsawa, A. Morita, and J. Takahashi. Fracture behaviour of carbon fibre reinforced polypropylene under artificial lightning strike. Presented at The 19th International Conference on Composite Materials, Montreal, Canada. July 2013. 
[18] R. Munoz, S. Delgado, C. Gonzalez, B. Lopez-Romano, D. Wang, and J. Llorca. Modelling lightning impact thermo-mechanical damage on composite materials. Applied Composite Materials, Vol. 21(10443-013-9377-9), pp. 149-164, 2014.

[19] A. Katunin, P. Sul, A. Łasica, K. Dragan, K. Krukiewicz, R. Turczyn. Damage resistance of CSA-doped PANI/epoxy CFRP composite during passing the artificial lightning through the aircraft rivet. Engineering Failure Analysis, Vol. 82, pp. 116-122, 2017

[20] G. F. Abdelal and A. Murphy, "A multiphysics simulation approach for efficient modeling of lightning strike tests on aircraft structures," IEEE Trans. Plasma Sci., vol. 45, no. 4, pp. 725-735, 2017.

[21] G. Abdelal, A. Murphy, Nonlinear numerical modelling of lightning strike effect on composite panels with temperature dependent material properties, Composite Structures, Vol. 109, Pages 268-278, 2014.

[22] T. Ogasawara, Y. Hirano, A. Yoshimura. Coupled Thermal-Electrical Analysis for Carbon Fiber/Epoxy Composites Exposed To Simulated Lightning Strike. Composites: Part A, Vol. 41, pp. 973-981, 2010.

[23] F. Wang, N. Ding, Z. Liu, Y. Ji, and Z. Yue. Ablation damage characteristic and residual strength prediction of carbon fibre/epoxy composite suffered from lightning strike. Composite Structures, Vol. 117, pp. 222-33, 2014.

[24] Q. Dong, Y. Guo, X. Sun, and Y. Jia. Coupled electrical-thermal-pyrolytic analysis of carbon fiber/epoxy composites subjected to lightning strike. Polymer, Vol. 56, pp. 38594, 2015.

[25] P. Foster, G. Abdelal, A. Murphy. Understanding how arc attachment behaviour influences the prediction of composite specimen thermal loading during an artificial 
lightning strike test. Computer Structures, In press, DOI: 10.1016/j.compstruct.2018.03.039

[26] P. Gineste, R. Clerc, C. Castanie, H. Andreu, and E. Buzaud. Assessment of Lightning Direct Effects Damages by Modelling Techniques. Presented at Int. Aerospace Ground Conf. on Lightning and Static Electricity, Pittsfield, USA. 2009.

[27] B. Lepetit, F. Soulas, S. Guinard, I. Revel, G. Peres, Y. Duval. Analysis of composite panel damages due to a lightning strike: mechanical effects. International Conference on Lightning and Static Electricity, SEA13-25.6, Seattle, USA, 2013

[28] B. Lepetit, C. Escure, S. Guinard, I. Revel, G. Peres, Y. Duval. Thermo-mechanical effects induced by lightning on carbon fiber composite materials. Int. Aerospace and Ground Conf. on Lightning and Static Electricity, Oxford, 2011

[29] Z. Liu, Z. Yue, F. Wang, Y. Ji. Combining analysis of coupled electrical-thermal and blow-off impulse effects on composite laminate induced by lightning strike. Applied Composite Materials. Vol. 22, Issue 2, pp 189-207, 2015

[30] P. Parlevliet, H. Bersee, and A. Beukers. Residual stresses in thermoplastic composites - a study of the literature - part i: Formation of residual stresses. Composites: Part A, Vol. 37, pp. 1847-57, 2006

[31] J. Compan, T. Hirai, G. Pintsuk, P. Broxtermann, N. Noda. Reduction of thermal shock induced damages in carbon fibre composites. Presented at 16th International Conference on Composite Materials, Kyoto, Japan, June 2007

[32] J. Compan, T. Hirai, G. Pintsuk, P. Broxtermann, N. Noda. Reduction of preferential erosion of carbon fibre composites under intense transient heat impulses. Presented at The 11th International Workshop on Plasma Facing Materials and Components for Fusion Applications, Greifswald, Germany, October 2006 
[33] J. Linke, H. Bolt, P. Cahppius, H. Penkalla, M. Scheerer. Brittle destruction of carbon based materials under severe thermal loads. Fusion Engineering and Design, Vol. 4950, pp. 235-242, 2000

[34] J. Linke, H. Bolt, R. Duwe, W. K"uhnlein, A. Lodato. High heat flux simulation experiments with improved electron beam diagnostics. Journal of Nuclear Materials, Vol. 283-287, pp. 1152-56, 2000

[35] T. Hirai, S. Brezinsek, W. Kuehnlein, J. Linke, G. Sergienko. Particle release from carbon based materials under intense transient heat loads. Presented at The 10th International Workshop on Carbon Materials for Fusion Applications, Julich, Germany, September 2003

[36] I. Daniel, B. Werner, and J. Fenner. Strain-rate-dependent failure criteria for composites. Composites Science and Technology, Vol. 71, pp. 357-64, 2011.

[37] M. Schlecht and K. Schulte. Advanced calculation of the room-temperature shapes of thin unsymmetric composite laminates. Composite Structures, Vol. 32, pp. 627-33, 1995.

[38] Y. Bai and T. Keller. Modelling of Mechanical Response of FRP Composites in Fire. Composites: Part A, Vol. 40, pp. 731-38, 2009.

[39] A. Gilat, R. Goldberg, and G. Roberts. Experimental Study of Strain-Rate-Dependent Behaviour of Carbon/Epoxy Composite. Composites Science and Technology, Vol. 61, pp. 1469-1476, 2002.

[40] J. Harding and C. Ruiz. The mechanical behaviour of composite materials under impact loading. Key Engineering Materials, Vol. 141-143, pp. 403-26, 1998.

[41] R. Ochola, K. Marcus, G. Nurick, and T. Franz. Mechanical Behaviour of Glass and Carbon Fibre Reinforced Composites at Varying Strain Rates. Composite Structures, Vol. 63, pp. 455-467, 2004. 
[42] Y. Shi, T. Swait, C. Soutis, Modelling damage evolution in composite laminates subjected to low velocity impact, Composite Structures, Vol. 94, Issue 9, Pages 29022913, 2012.

[43] V.A. Phadnis, P. Kumar, A. Shukla, A. Roy, V.V. Silberschmidt. Optimising curvature of carbon fibre-reinforced polymer composite panel for improved blast resistance: Finite-element analysis, Materials \& Design, Vol. 57, pp. 719-727, 2014.

[44] P. Naghipour, E.J. Pineda, S.M. Arnold. Simulation of Lightning-Induced Delamination in Un-protected CFRP Laminates. Applied Composite Materials. Vol. 23, Issue 4, pp. 523-535, 2016.

[45] J.J. Yin, F. Chang, S.L. Li, X.L. Yao, J.R. Sun, Y. Xiao. Lightning Strike Ablation Damage Influence Factors Analysis of Carbon Fiber/Epoxy Composite Based on Coupled Electrical-Thermal Simulation. Applied Composite Materials, Vol. 24, Issue 5, pp. 1089-1106, 2017.

[46] J.J. Yin, F. Chang, S.L. Li, X.L. Yao, J.R. Sun, Y. Xiao. Experimental and Numerical Simulation Analysis of Typical Carbon Woven Fabric/Epoxy Laminates Subjected to Lightning Strike. Applied Composite Materials, Vol. 24, Issue 6, pp. 1353-1372, 2017.

[47] J. J. Yin, S. L. Li, X. L. Yao, F. Chang, L. K. Li, X. H. Zhang. Lightning Strike Ablation Damage Characteristic Analysis for Carbon Fiber/Epoxy Composite Laminate with Fastener. Applied Composite Materials, Vol. 23, Issue 4, pp 821-837, 2016.

[48] R. Bogenfeld, J. Kreikemeier, T. Wille. Review and benchmark study on the analysis of low-velocity impact on composite laminates. Engineering Failure Analysis, Vol. 86, pp. 72-99, 2018.

[49] A. Puck and H. Schurmann. Failure analysis of frp laminates by means of physically based phenomenological models. Composites Science and Technology, 58:1045-67, 1998. 
[50] M.L. Benzeggagh and M. Kenane. Measurement of Mixed-mode Delamination Fracture Toughness of Unidirectional GlassEpoxy Composites with Mixed-mode Bending Apparatus, Composites Science and Technology, Vol. 56, pp. 439-449, 1996. 
Tables

Table 1 - Predicted peak stresses and strains.

\begin{tabular}{|c|c|c|}
\hline & $\begin{array}{c}\text { Temperature dependent } \\
\text { material properties }\end{array}$ & $\begin{array}{c}\text { Temperature and } \\
\text { temperature rate } \\
\text { dependent material } \\
\text { properties }\end{array}$ \\
\hline $\begin{array}{c}\text { Ply fibre direction (11) } \\
(\mathrm{MPa})\end{array}$ & -41 & -45 \\
\hline $\begin{array}{c}\text { Ply transverse direction }(22) \\
(\mathrm{MPa})\end{array}$ & -60 & -115 \\
\hline $\begin{array}{c}\text { Ply through-thickness direction }(33) \\
(\mathrm{MPa})\end{array}$ & 13 & -11 \\
\hline $\begin{array}{c}\text { Ply fibre direction }(\mathrm{XX}) \\
(\mu \varepsilon)\end{array}$ & 0.2 & 200 \\
\hline $\begin{array}{c}\text { Ply transverse direction }(\mathrm{YY}) \\
(\mu \varepsilon)\end{array}$ & 4,200 & 3,300 \\
\hline $\begin{array}{c}\text { Ply through-thickness direction }(\mathrm{ZZ}) \\
(\mu \varepsilon)\end{array}$ & 41,700 & 54,600 \\
\hline
\end{tabular}

Table 2 - Predicted peak transverse stresses and through-thickness strains under different strain rates

\begin{tabular}{|c|c|c|c|}
\hline Strain rate & $\begin{array}{c}\text { Preceding result } \\
\text { (no strain rate effect } \\
\text { modelled) }\end{array}$ & $1 \times 10^{3} \mathrm{~s}^{-1}$ & $1 \times 10^{4} \mathrm{~s}^{-1}$ \\
\hline $\begin{array}{c}\text { Maximum transverse } \\
\text { stress } \sigma_{22} \\
(\mathrm{MPa})\end{array}$ & -115 & -167 & -201 \\
\hline $\begin{array}{c}\text { Maximum through } \\
\text { thickness strain } \varepsilon_{\mathrm{zz}} \\
(\mu \varepsilon)\end{array}$ & 54,600 & 53,700 & 54,200 \\
\hline
\end{tabular}




\section{Figures}

Specimen B-4

Specimen C2-1

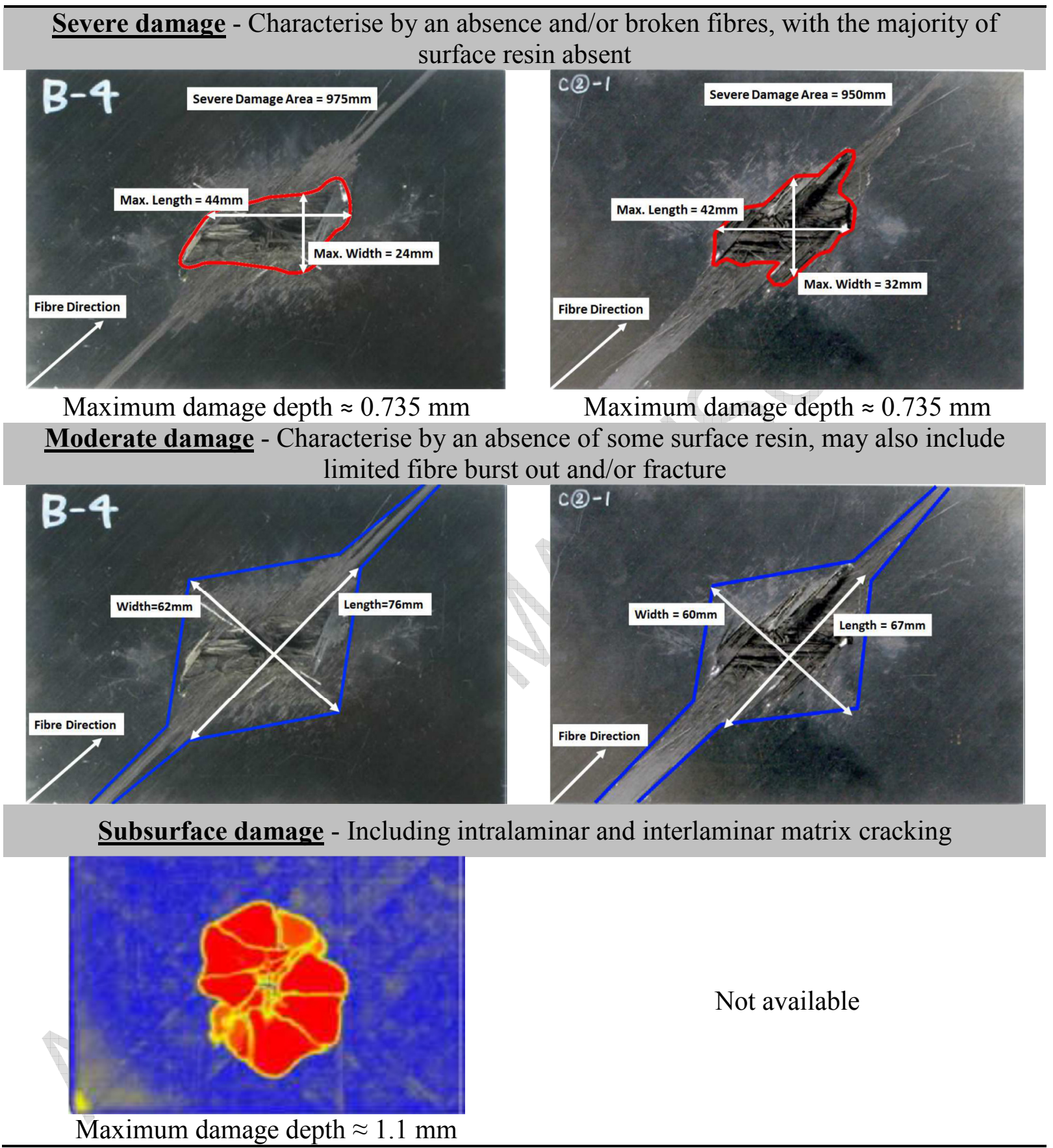

Figure 1 - Three damage areas as identified from experiment with a peak current is 40kA, rise time from $10 \%$ to $90 \%$ of maximum current is $4 \mu$ s and time through to $50 \%$ of maximum current is $20 \mu \mathrm{s}$. 
Load Editor

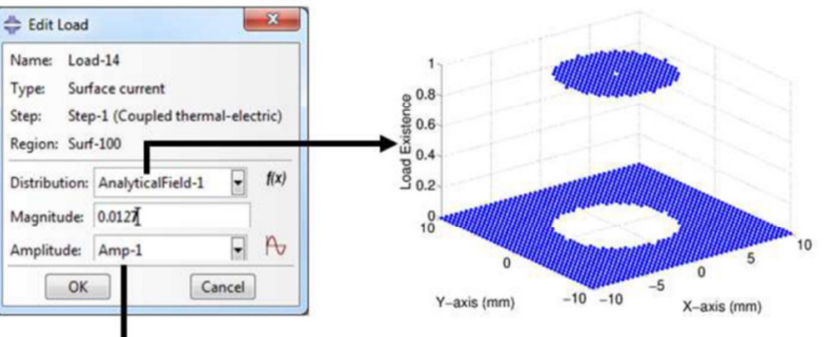

Amplitude:

Defines the load amplitude for the time during which this area is needed. Otherwise this load is zero.

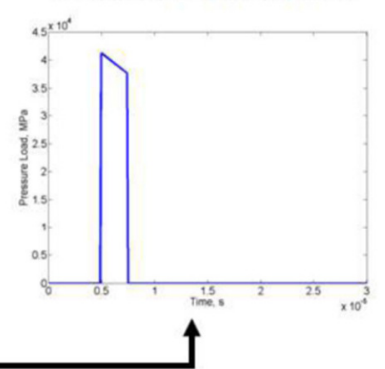

a)

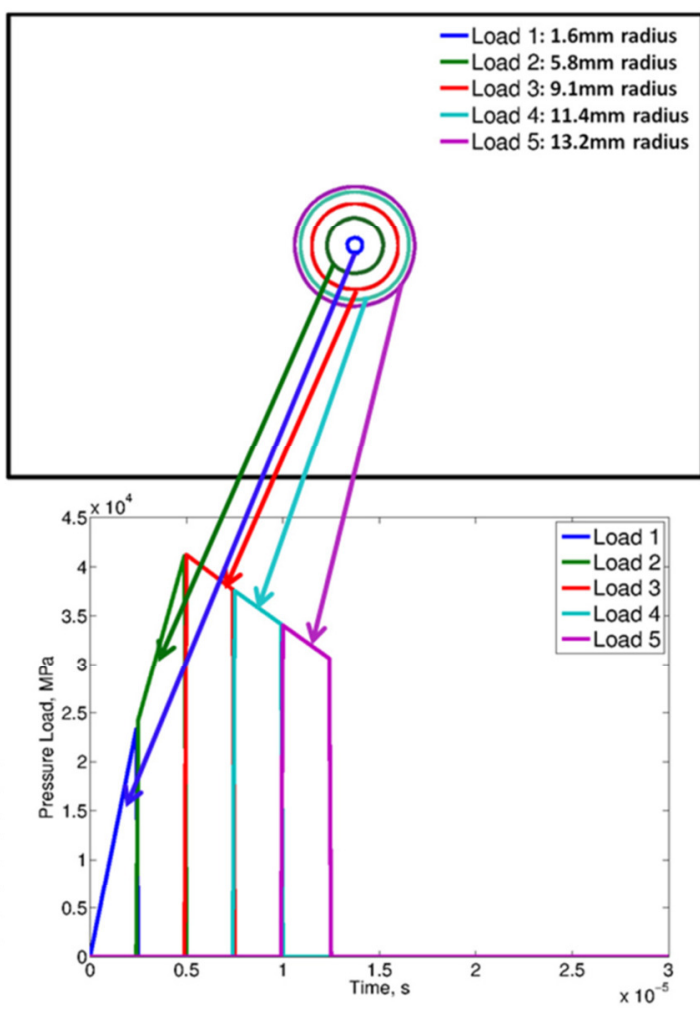

b)

Figure 2 - The implementation of the expanding arc radius: a) load editor through which the electrical surface current load is applied, b) illustrative example of a static circular expanding arc (first five loads). 


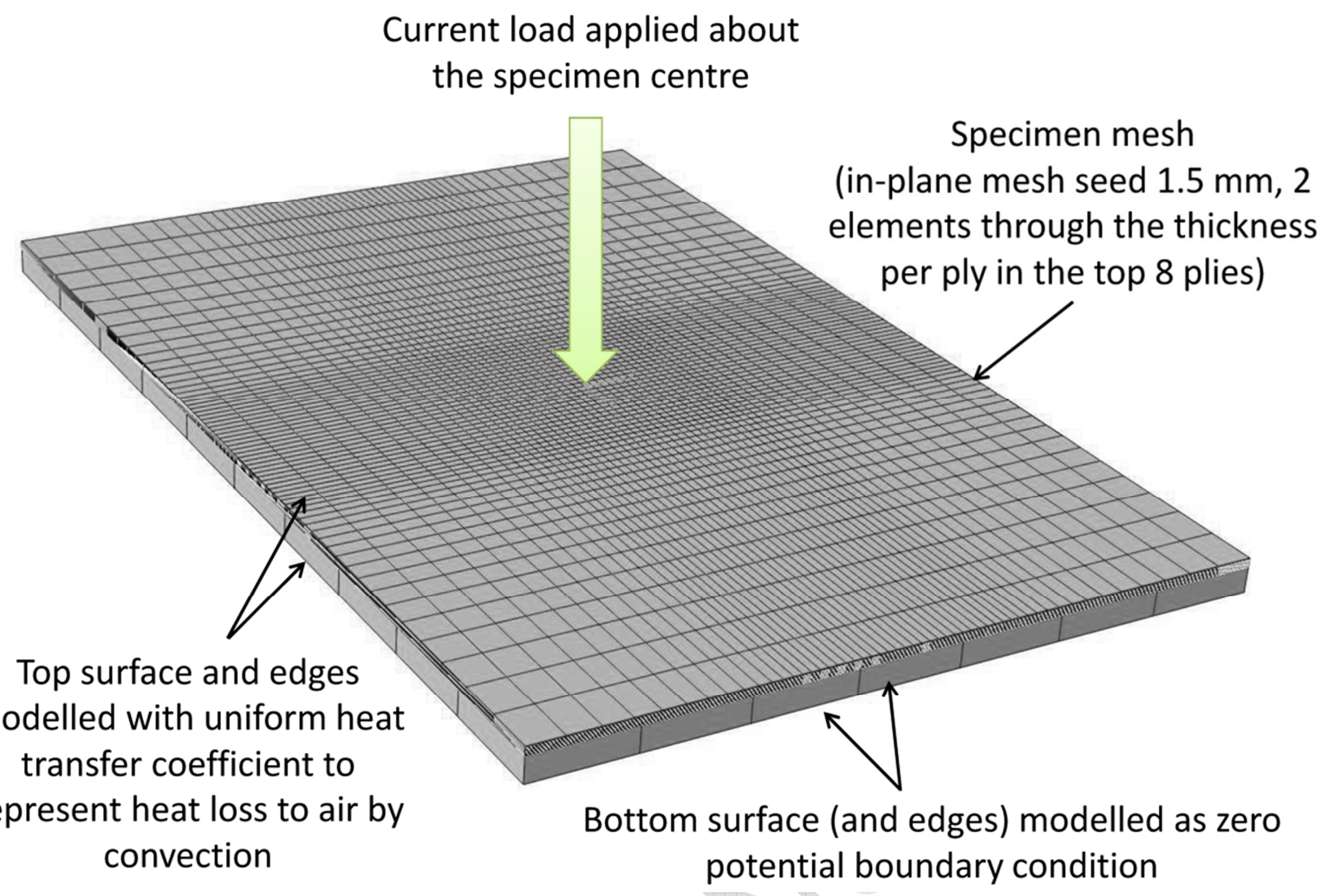

Figure 3 - Specimen mesh plus overview of analysis loading and boundary conditions. 


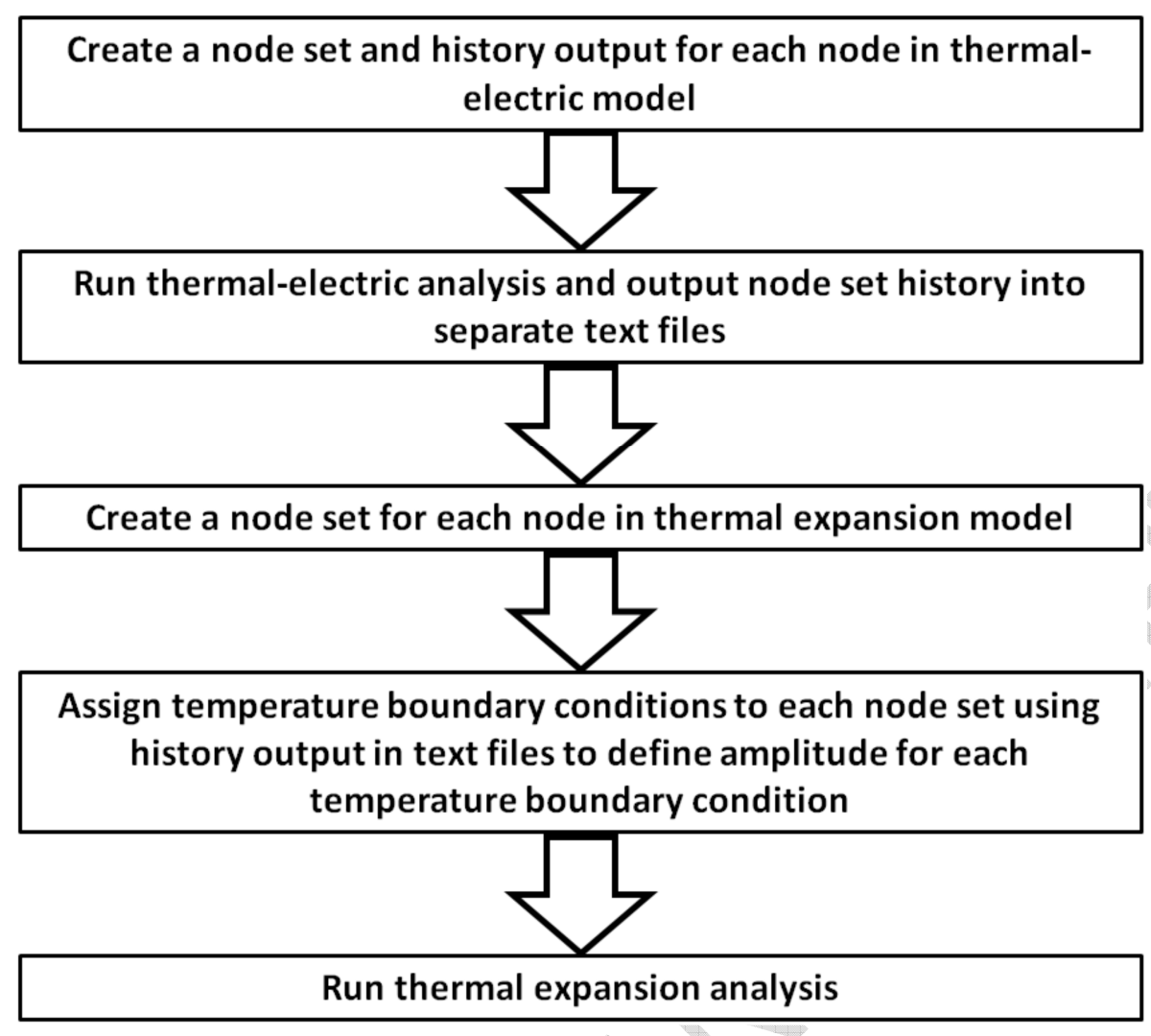

Figure 4 - Flow chart of steps required to transfer time and temperature data for each node from the thermal-electric output file to the thermal expansion model. 


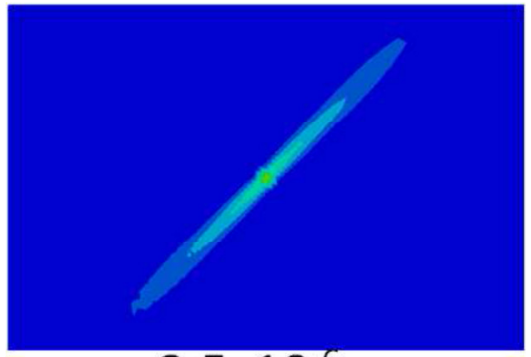

$2.5 \times 10^{-6} \mathrm{~s}$

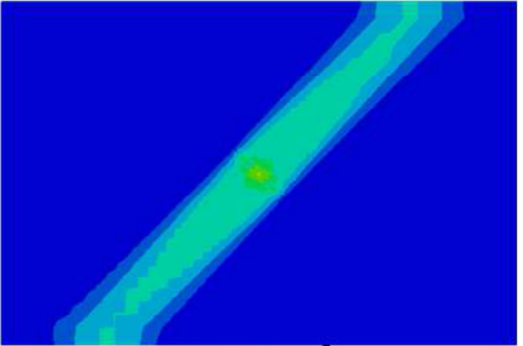

$5.0 \times 10^{-6} \mathrm{~s}$

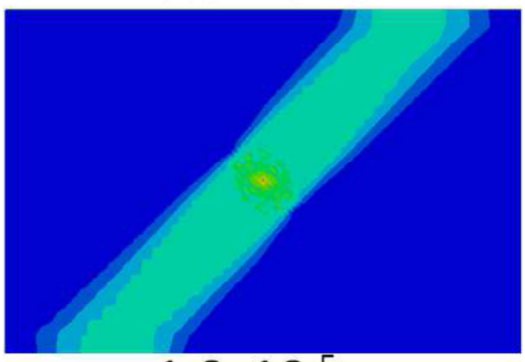

$1.0 \times 10^{-5} \mathrm{~s}$

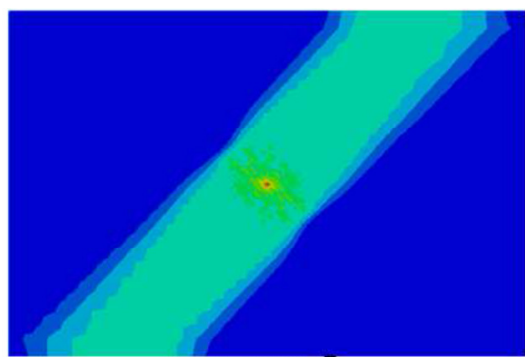

$1.5 \times 10^{-5} \mathrm{~s}$

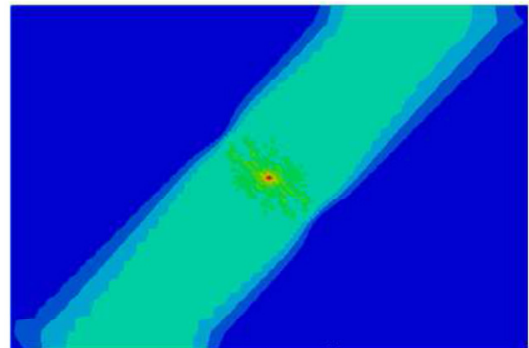

$2.0 \times 10^{-5} \mathrm{~s}$

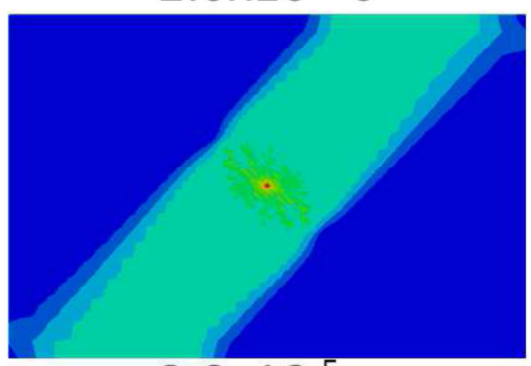

$3.0 \times 10^{-5} \mathrm{~s}$

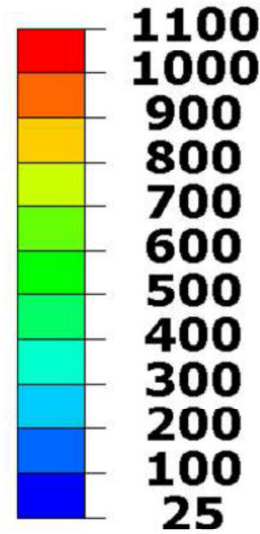

a)

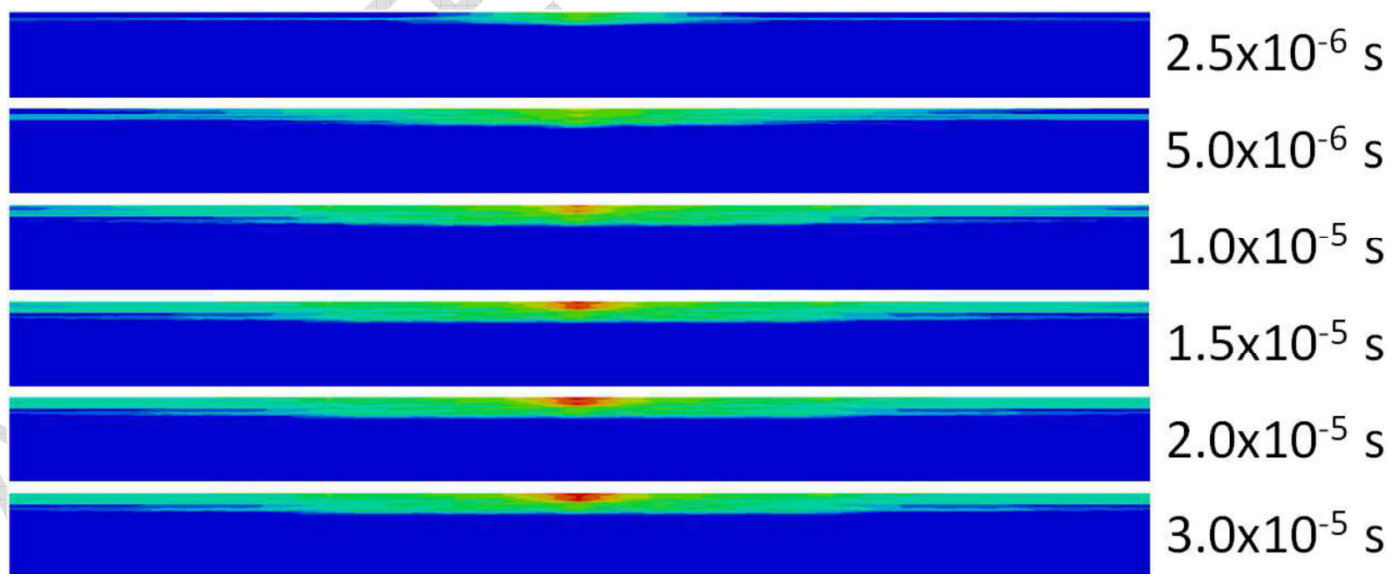

b)

Figure 5 - Temperature development $\left({ }^{\circ} \mathrm{C}\right)$ in the specimen during the thermal-electric analysis; a) Top surface view, b) Cross-sectional view through the middle of the specimen. 


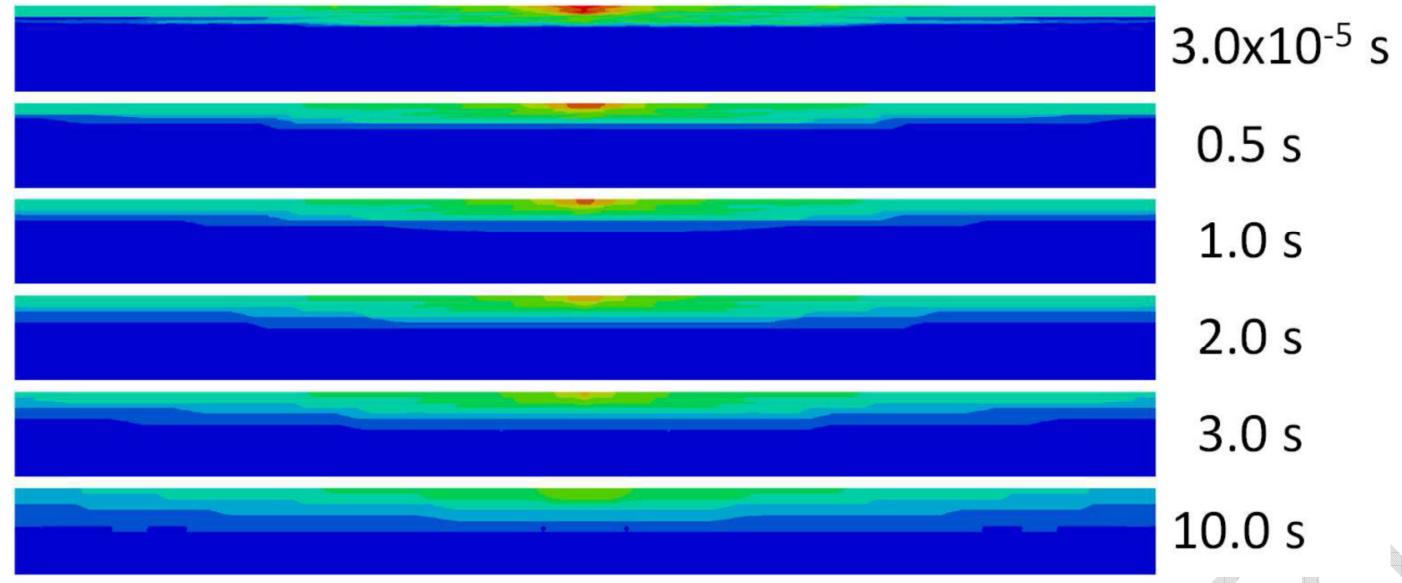

Figure 6 - Temperature development $\left({ }^{\circ} \mathrm{C}\right)$ in the specimen during the heat transfer analysis step. 

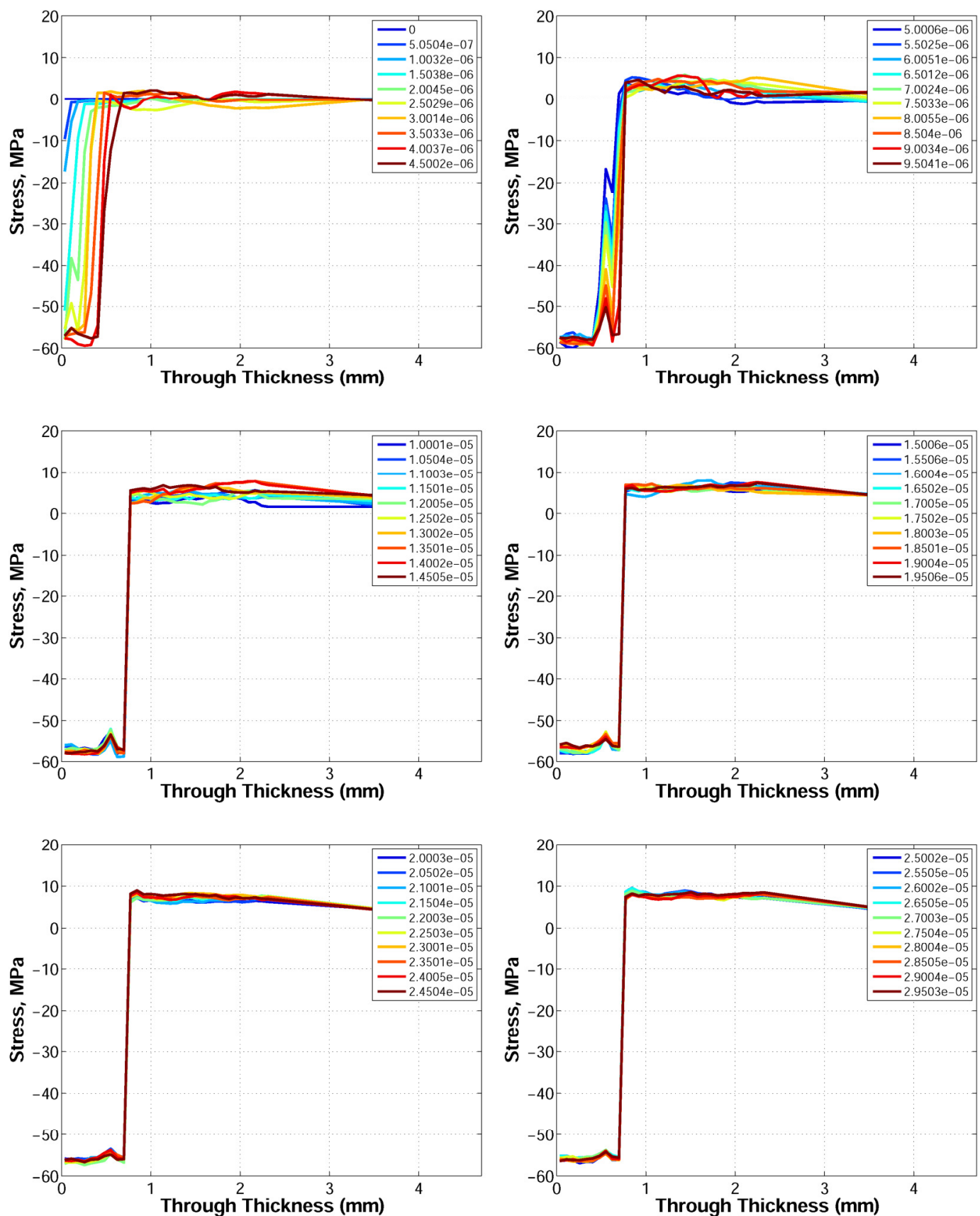

Figure 7 - Ply transverse fibre direction stress $\left(\sigma_{22}\right)$ through the thickness of the specimen at the specimen centre. For sixty time steps from the beginning of the thermal expansion analysis to $3 \times 10^{-5} \mathrm{~s}$. Each time step is denoted by one of the coloured lines. 

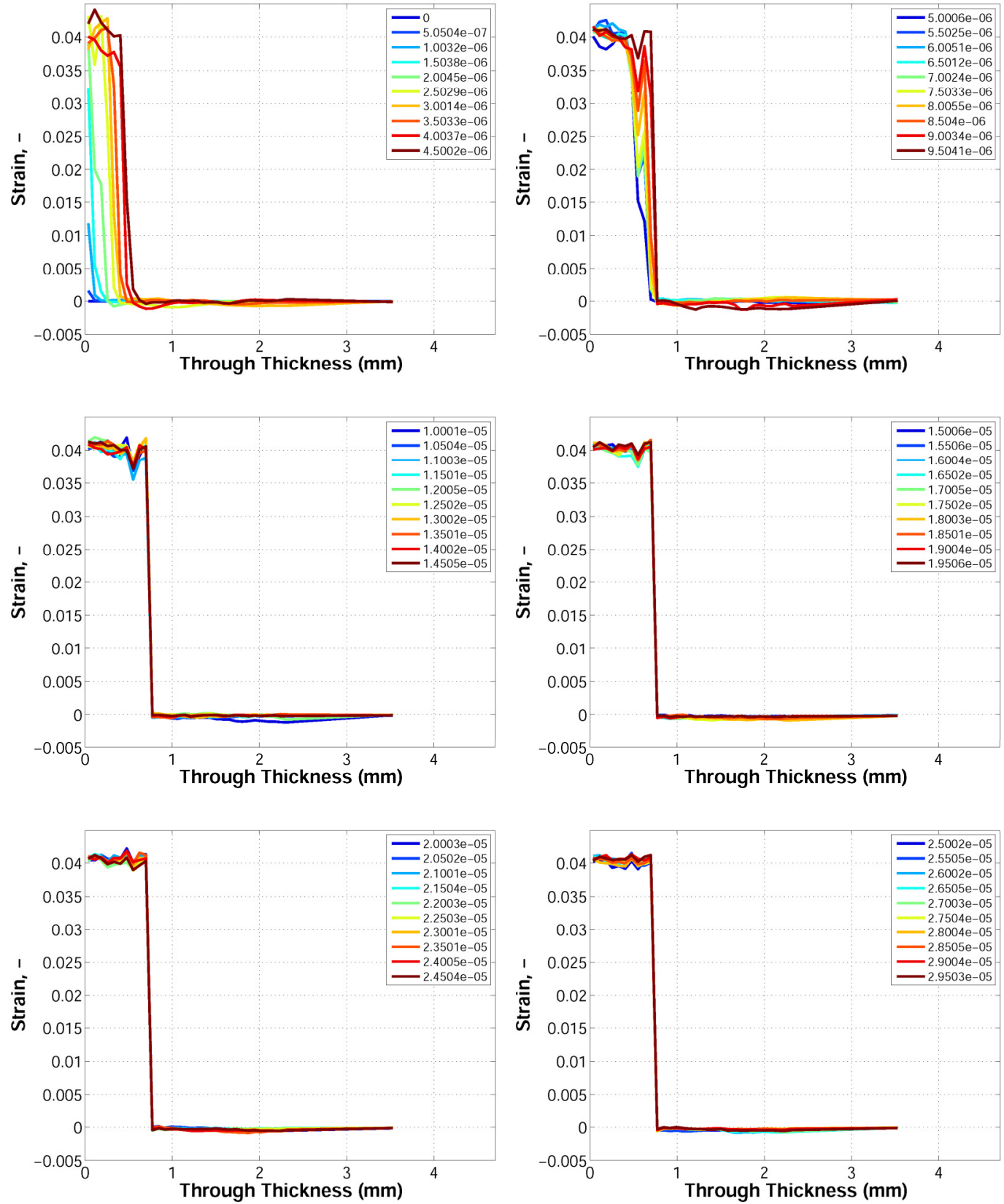

Figure 8 -Ply through-thickness direction strain $\left(\varepsilon_{\mathrm{zz}}\right)$ through the thickness of the specimen at the specimen centre. For sixty time steps from the beginning of the thermal expansion analysis to $3 \times 10^{-5} \mathrm{~s}$. Each time step is denoted by one of the coloured lines. 


\section{Top ply Damage - Strain based through-thickness failure}

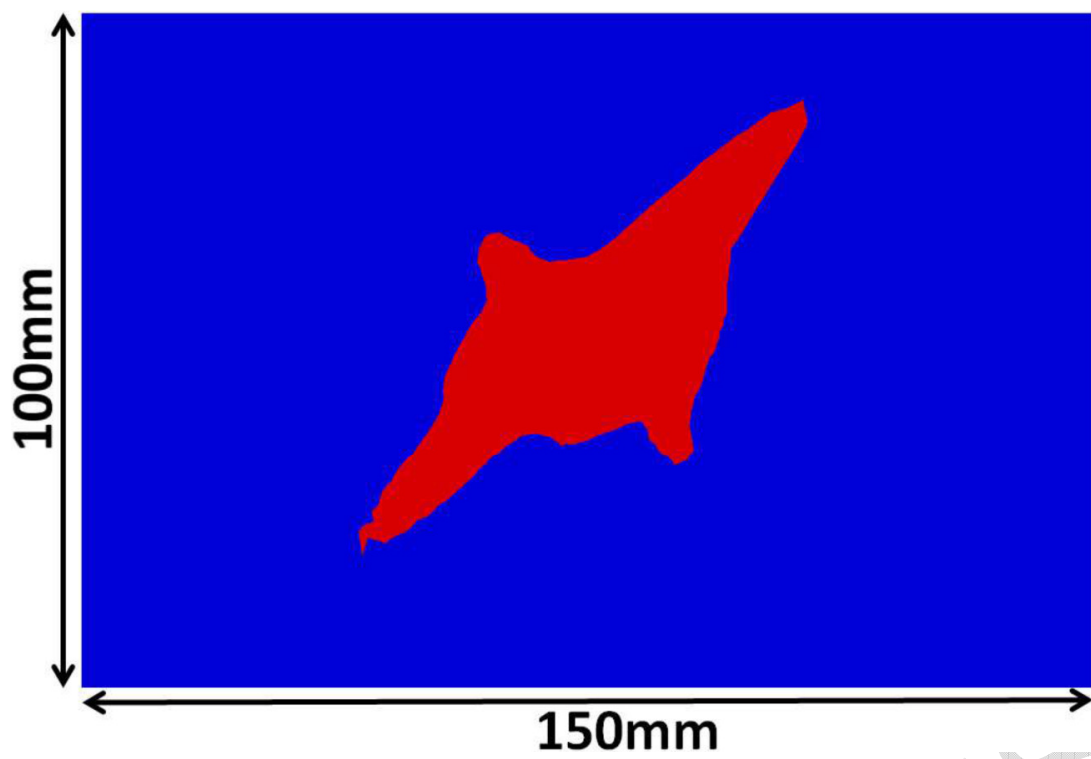

Surface Area $=$ $1485 \mathrm{~mm}^{2}$

\section{Damage over top 5 plies}

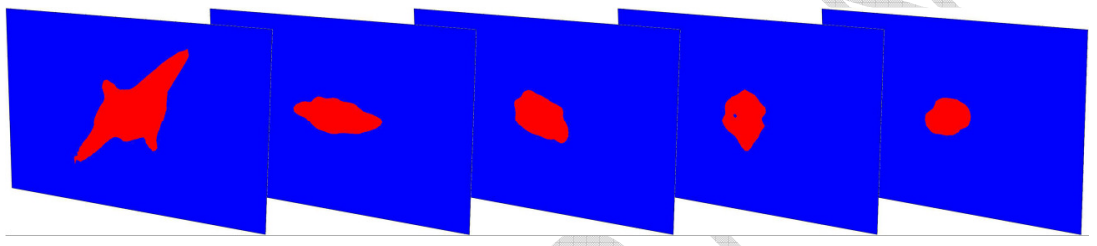

Depth of damage $=$ $0.735 \mathrm{~mm}$ (5 plies)

Figure 9 - Failure prediction - modelling temperature dependent material properties only. 


\section{Top ply Damage - Stress based transverse failure}

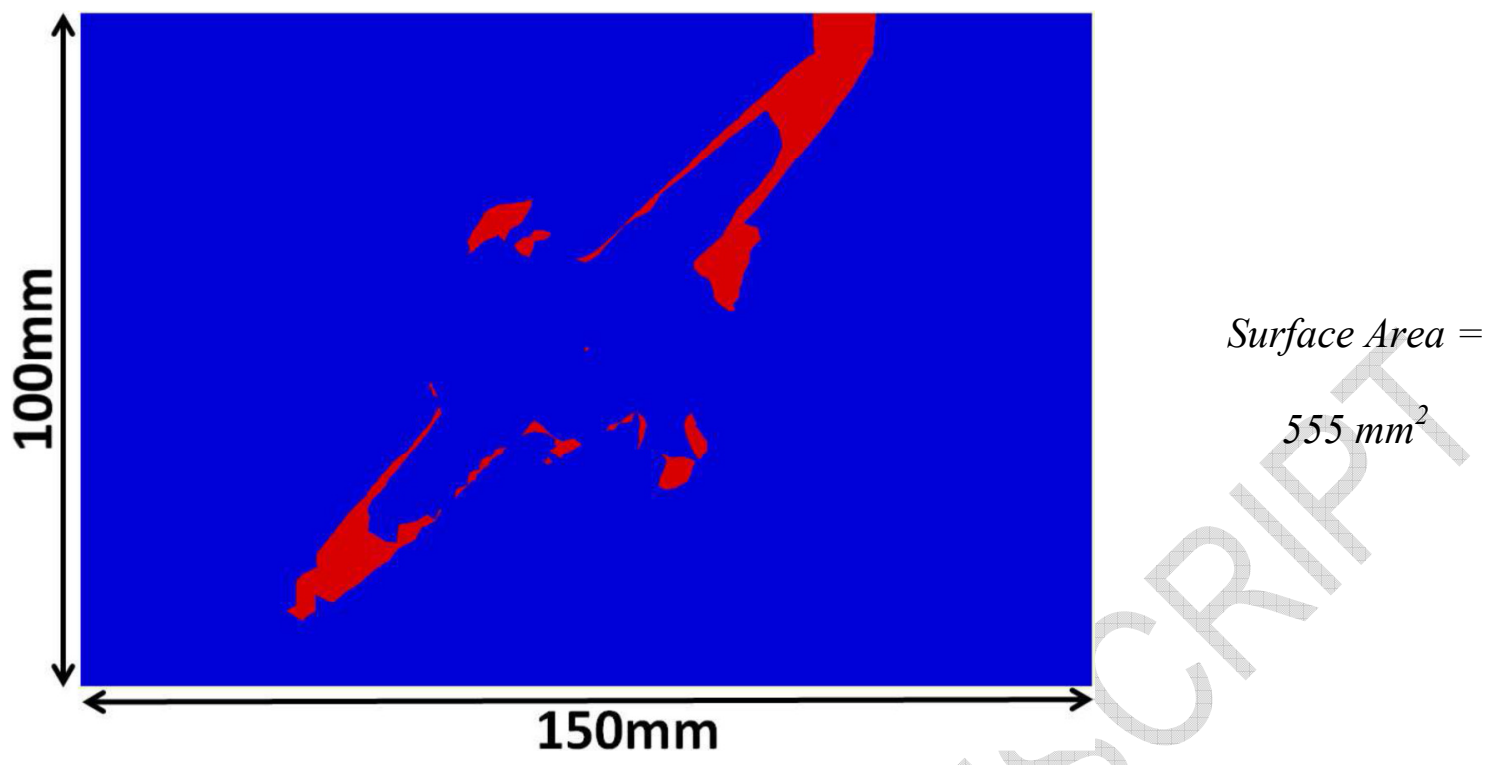

Top ply Damage - Strain based through-thickness failure

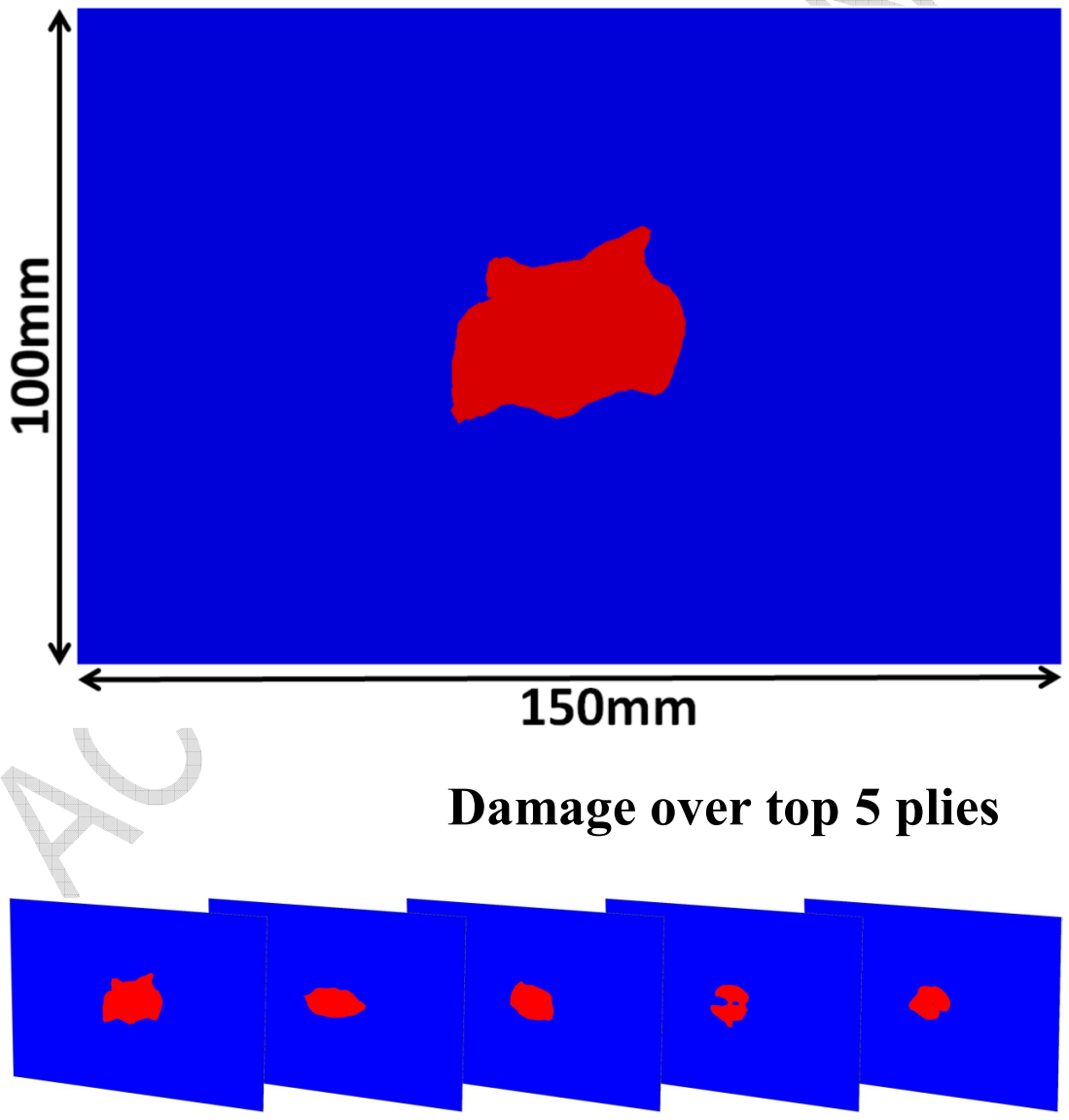

Surface Area $=$

$720 \mathrm{~mm}^{2}$

Depth of damage $=$

$0.735 \mathrm{~mm}$

(5 plies)

Figure 10 - Failure predictions - modelling temperature and temperature rate dependent material properties. 

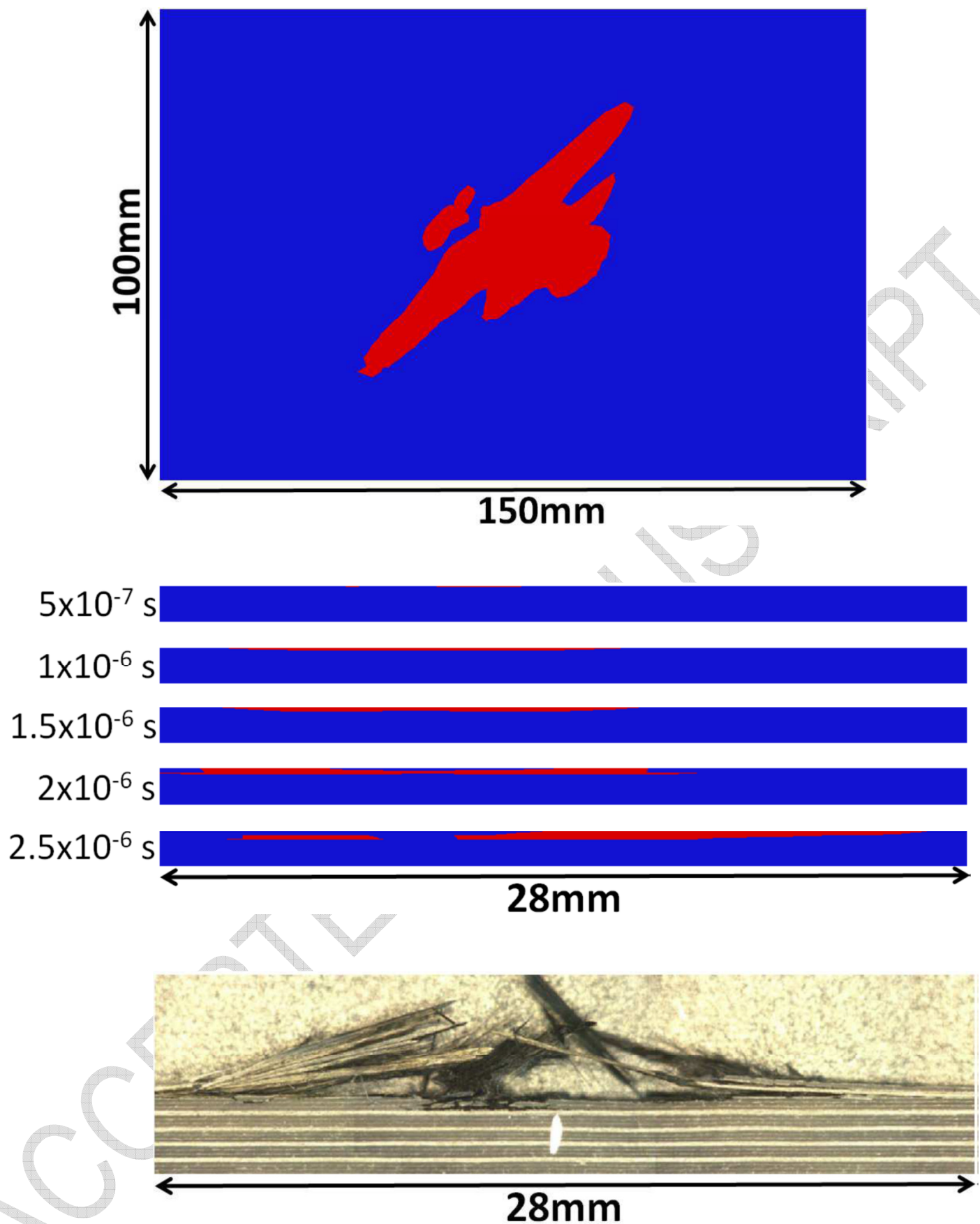

Figure 11 - Total area of the specimen with a strain rate greater than $10^{4} \mathrm{~s}^{-1}$ (total area equal to $1080 \mathrm{~mm}^{2}$ ). 

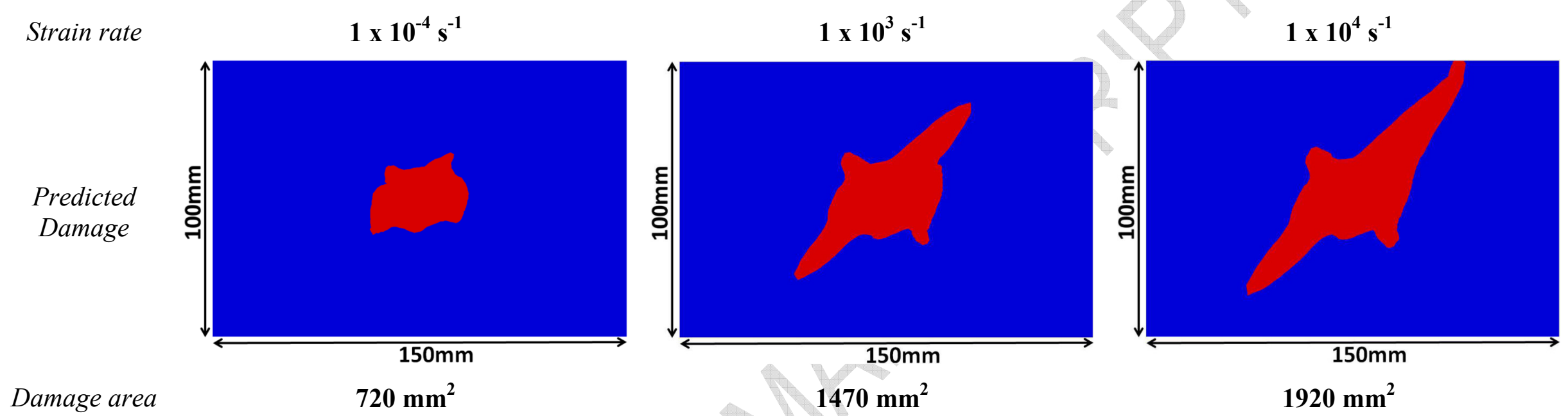

Figure 12 - Comparison of predicted failure with assumed strain rate material models. 